\title{
HOST SELECTION AND SPECIES PREFERENCE OF THE RED-BILLED OXPECKER BUPHAGUS ERYTHRORHYNCHUS IN THE KRUGER NATIONAL PARK
}

\section{J. H. GROBLER}

\author{
Department of Research and Information \\ National Parks Board of Trustees \\ Private Bag X66 \\ Cradock \\ 5880
}

Abstract - The host selection and species preference of the Redbilled Oxpecker was investigated during January and February 1979, in the southern portion of the Kruger National Park, Republic of South Africa. A total of 19 species of larger mammals were looked at and of these 11 were utilised as hosts. Giraffe Giraffa camelopardalis, were found to be the most important host and ranked well above the others as a preferred species. Published data on oxpeckers were reviewed with the view to possible translocation of the birds as a measure to increase their now limited distribution.

\section{Introduction}

Two species of oxpeckers occur in Africa, the Red-billed Oxpecker Buphagus erythrorhynchus and the Yellow-billed Oxpecker B. africanus. Both species have experienced a reduction in range since the turn of the century (Clancey 1964; Brooke 1963; Smithers 1964; Attwell 1966; Stutterheim 1976; and Grobler in press). Although not documented, the range restriction has undoubtedly been due to elimination of large game and agricultural pursuits, in particular cattle dipping which not only poisons the birds, but also deprives them of their basic food source (ticks).

In the Republic of South Africa the Red-billed Oxpecker is now restricted to the larger game areas in the northeast of the country.

The diet of oxpeckers consists almost entirely of ticks, but also includes biting flies, raw flesh and blood (Moreau 1933; Van Someren 1951; Olivier \& Laurie 1974; Stutterheim 1976). This food source is obtained directly off various large mammals with which the oxpeckers have formed a close association. What makes these birds even more remarkable is that they have on them certain ticks which are normally eaten as food (Stutter- 
heim 1977a), a unique example of a prey species parasitising their predator.

Although host selection by oxpeckers has been recorded by various authors (Attwell 1966; Buskirk 1975; Stutterheim 1976; Grobler in press), the only objective study showing host preference has been by Grobler \& Charsley (in press) on the Yellow-billed Oxpecker. The present study set out to determine host selection and species preference shown by the Redbilled Oxpecker in the Kruger National Park (KNP). No yellow-billed oxpeckers are known to occur in the KNP (Stutterheim 1976). The study took place during January and February of 1979 and did not lend itself to showing seasonal changes in selection and preference if these do exist.

All larger mammals excluding the primates, carnivores and elephant Loxodonta africana were counted along predetermined routes in the southern portion of the KNP, providing they were clearly visible. The survey took place at different times during the day and all oxpeckers present on hosts were counted and classified into adults and juveniles. Although juveniles are slightly smaller than adults (see Stutterheim 1977b), they can also be clearly distinguished from adults by their colouration (see Stutterheim, Mundy \& Cook 1976). Elephants were considered as non-hosts. Although piapiacs Ptilostamnus afer occur on elephants in East Africa (Rice 1963), only one fortuitous record of an oxpecker on an elephant was recorded in Zambia (Benson \& White 1957).

Because of the large numbers of impala Aepyceros melampus in the study area, a sample count of at least 1000 individuals was taken once a week for three weeks. Game in the large paddocks near Pretoriuskop in the south western corner of the KNP, were also looked at as they contained some of the rarer species of ungulates. These results were considered separately as a higher than average tick density in the paddocks may have influenced the results.

No counting took place at water holes as oxpeckers have a tendency to gather at these points and sometimes only use animals as a platform to gain access to the water. A higher density of red-billed oxpeckers also occurs on animals within $500 \mathrm{~m}$ of water (Stutterheim 1976).

Results

\section{Host selection}

Stutterheim (1976) states that in the KNP oxpeckers utilise 15 different mammal species, but he only lists eleven of these in one table. Of the 19 species observed during the present study, only 11 were utilised by the Red-billed Oxpecker (Tables 1 and 2). These are the same as those listed by Stutterheim (op. cit.), and were impala, giraffe Giraffa camelopardalis, buffalo Syncerus caffer, kudu Tragelaphus strepsiceros, blue wildebeest Connochaetes taurinus, warthog Phacochoerus aethiopicus, zebra Equus burchelli, sable 
Table 1

Host selection and species preference of the Red-billed Oxpecker (Buphagus erythrorhynchus) in the Kruger National Park, January and February 1979

\begin{tabular}{lccc}
\hline Ungulate species & No. animals & No. birds & P.I.* $^{*}$ \\
\hline Giraffe Giraffa camelopardalis & 153 & 169 & 0,90 \\
Sable Hippotragus niger & 37 & 12 & 3,08 \\
Kudu Tragelaphus strepsiceros & 195 & 26 & 7,50 \\
Buffalo Syncerus caffer & 339 & 39 & 8,69 \\
Wildebeest Connochaetes taurinus & 111 & 3 & 37,00 \\
Warthog Phacochoerus aethiopicus & 397 & 9 & 44,11 \\
Impala Aepyceros melampus & 3054 & 55 & 55,53 \\
Hippopotamus Hippopotamus amphibius & 39 & 0 & - \\
White rhino Ceratotherium simum & 3 & 0 & - \\
Waterbuck Kobus ellipsiprymnus & 135 & 0 & - \\
Reedbuck Redunca arundinum & 18 & 0 & - \\
Bushbuck Tragelaphus scriptus & 16 & 0 & - \\
Steenbok Raphicerus campestris & 52 & 0 & - \\
Duiker Sylvicapra grimmia & 15 & 0 & - \\
Zebra Equus burchelli & 199 & 0 & - \\
\hline
\end{tabular}

*P.I. $=$ preference index $=\frac{\text { number of animals }}{\text { number of birds }}$

Table 2

Ungulates and Red-billed Oxpeckers (Buphagus erythrorhynchus) counted in the Pretoriuskop paddocks, Kruger National Park, January and February 1979

\begin{tabular}{lccc}
\hline Ungulate species & No. animals & No. birds & P.I.* $^{*}$ \\
\hline Eland Taurotragus oryx & 20 & 15 & 1,33 \\
Roan Hippotragus equinus & 18 & 7 & 2,57 \\
White rhino Ceratotherium simum & 13 & 2 & 6,50 \\
Zebra Equus burchelli & 6 & 1 & 6,00 \\
Tsessebe Damaliscus lunatus & 31 & 0 & - \\
Wildebeest Connochaetes taurinus & 2 & 0 & - \\
Warthog Phacochoerus aethiopicus & 1 & 0 & - \\
Reedbuck Redunca arundinum & 3 & 0 & - \\
Oribi Ourebia ourebi & 1 & 0 & - \\
Steenbok Raphicerus campestris & 4 & 0 & - \\
\hline
\end{tabular}

*P.I. $=$ preference index $=\frac{\text { number of animals }}{\text { number of birds }}$

Hippotragus niger, roan $H$. equinus, white rhino Ceratotherium simum and eland Taurotragus oryx.

Those not observed being utilised during the survey (although some of the samples were small) were waterbuck Kobus ellipsiprymnus, reedbuck Reduca arundinum, bushbuck Tragelaphus scriptus, tsessebe Damaliscus lunatus, 
steenbok Raphicerus campestris, duiker Sylvicapra grimmia, oribi Ourebia ourebi and hippopotamus Hippopotamus amphibius.

This corresponds well with the findings of Attwell (1966) except for the hippopotamus. Unfortunately all but one of this species looked at during the present study were basking in water. On one occasion during the study period a group of five hippo were observed at close range and after about an hour, one adult oxpecker landed on the back of one of the hippo in the water, stayed momentarily, then flew off again. Red-billed oxpeckers commonly use hippo basking on banks in the Wankie National Park and Lundi River in Rhodesia (pers. obs.). They are also well used in Zambia, even in the water (Attwell 1966) although Pitman (1956) does not regard them as habitual hosts in Uganda. Feeding on the hippopotamus is mostly in the form of wound feeding (Rice 1963; Attwell 1966; Olivier \& Laurie 1974).

Fortuitous single observations of one oxpecker on bushbuck, reed buck and waterbuck are listed by Attwell (1966). The reason why certain ungulates are not used remains speculative but appears to be related to the size of certain species (e.g. steenbok, duiker, oribi), habitat utilised (e.g. bushbuck), wooly coats (e.g. waterbuck, reedbuck) and possible intolerance coupled with low tick density (e.g. tsessebe).

\section{Species preference}

Some species of ungulates were used more often than others. To illustrate this a preference index (PI) was calculated on the basis of one bird per number of individuals of a host species

$$
\text { i.e. P.I. }=\frac{\text { number of hosts counted }}{\text { number of oxpeckers counted }}
$$

If the PI for a particular animal was 10 , there was a mean expectancy of one oxpecker to every 10 animals counted.

Giraffe were by far the most popular (Table 1). Apart from the large surface area and short hair which may favour oxpecker feeding, the giraffe in the study area had an excessive number of external parasites and numerous scars on their necks. This possible super-abundance of food may have influenced the results to some degree.

Eland and roan were only seen in the paddocks near Pretoriuskop but were by all indications major hosts to red-billed oxpeckers in the KNP. This is in agreement with data presented in Stutterheim (1976). The kudu in the study area were regular hosts but not used to the same extent as indicated by Attwell (1966). Buffalo were also regular hosts but certainly not used to the same extent as in the Yellow-billed Oxpecker (see Grobler \& Charsley in press).

Impala, warthog and blue wildebeest were used infrequently and the only zebra seen with an oxpecker in attendance during the study period, was in the paddocks. A small sample of white rhino $(n=3)$ outside the 
paddocks did not have oxpeckers while 13 inside the paddocks had only two birds in attendance. Trails Ranger (T. Dearlove) was asked to record relevant data on one of his trails, during the study period. He recorded 11 rhino, none of which had oxpeckers on them. Thus on the 27 white rhino seen there were only two birds. This is indeed surprising in view of the known association between oxpeckers and rhino (see Attwell 1966).

Stutterheim (1976) provides data on eight ungulate species for 1973, showing number of hosts in relation to number of oxpeckers in his discussion on host utilisation near and away from water. Assuming this to be a random sample which included all ungulate sightings regardless of whether oxpeckers were in attendance or not, preference indices were calculated from his "away from water" data for comparative purposes (Table 3).

\section{Table 3}

Red-billed Oxpecker (Buphagus erythrorhynchus) host preference on eight ungulate species in the Kruger National Park

\begin{tabular}{lrr}
\hline Ungulate species & P.I.(1) & P.I.(2) \\
\hline Giraffe Giraffa camelopardalis & 0,90 & 0,61 \\
Sable Hippotragus niger & 3,08 & 1,15 \\
White rhino Ceratotherium simum & nil $(\mathrm{n}=3)$ & 0,92 \\
Kudu Tragelaphus strepsiceros & 7,50 & 5,37 \\
Wildebeest Connochaetes taurinus & 37,00 & 14,46 \\
Warthog Phacochoerus aethiopicus & 44,11 & 24,36 \\
Impala Aepyceros melampus & 55,53 & 29,24 \\
Zebra Equus burchelli & nil $(\mathrm{n}=199)$ & 7,90 \\
\hline
\end{tabular}

*P.I. $=$ preference index $=\frac{\text { number of animals }}{\text { number of birds }}$

P.I.(1) = data from present study

P.I.(2) = data from Stutterheim (1976), Table 10 p 48, "relationship away from water" figures used.

There was a marked difference in the results except for giraffe (assuming same group size and standard deviation for 1973 data, $\mathrm{t}=0,904, \mathrm{df}=$ 216, $\mathrm{P}=0,366$ ) and kudu (same assumptions as giraffe, $\mathrm{t}=\mathrm{O}, \mathrm{df}=130$, $\mathrm{P}=0,999)$ where no significant difference was found. All other results differed significantly. The rhino sample in the present study was too small to be meaningful, but the results for zebra cannot be explained. In the present study 199 zebra seen outside the Pretoriuskop paddocks had no oxpeckers on them while the data from Stutterheim (1976) indicate that on average, one in eight zebra should have an oxpecker in attendance. The overall difference in the results from the present study and that of Stutterheim may be due to a lower density of oxpeckers although this is purely speculative. The only indication of a possible lower density is that Stutterheim recorded a recruitment rate of 0,80 juveniles per adult in the 
$1973 / 74$ breeding season and 0,50 juveniles per adult in the 1974/75 breeding season. In the present study 340 oxpeckers were recorded, 84 $(24,70 \%)$ of these were juvenile which was equivalent to 0,33 juveniles per adult.

\section{Discussion}

Ungulate hosts utilised by oxpeckers may be divided into three categories: (i) key hosts, (ii) major hosts, and (iii) minor hosts. Key hosts are those most frequently utilised by the oxpeckers and are probably directly responsible for maintaining an oxpecker population in an area. The giraffe is certainly the key host to the Red-billed Oxpecker in the KNP, and is especially important in terms of food supply. Stutterheim (1976) showed that $85 \%$ of oxpecker activity on giraffe was devoted to feeding. Of the birds counted during the present study, $49,7 \%$ were seen on giraffe. The giraffe represented $3,21 \%$ of the animals counted.

Major hosts are those less frequently used, but still used on a regular basis. In the present study these included eland, roan, sable, kudu and buffalo. The results from data of Stutterheim (1976) would place white rhino and zebra in this category.

Minor hosts are those infrequently used. These were blue wildebeest, warthog, impala, white rhino and zebra in the present study. It is of interest that $75 \%$ of oxpecker activity on white rhino was devoted to resting, sun bathing and comfort movements, and only $25 \%$ on feeding (Stutterheim 1976). The hippopotamus would probably also fit into this category.

Quite what the ecological separations are between red-billed and yellow-billed oxpeckers are, is not entirely clear but probably lies in the mode of feeding. Differences in mandibles and methods of feeding have been described by several authors (Goodwin 1963; Attwell 1966; Stutterheim 1976). There is also a difference in host selection although a certain amount of overlap does occur. Buffalo, for example, are by all indications, the key host to the Yellow-billed Oxpecker (see Buskirk 1975; Grobler \& Charsley in press.). It could be that buffalo numbers dropped to a density too low to maintain yellow-billed oxpeckers sometime during the history of the KNP resulting in their extinction in the area.

The presence of key hosts would be an essential requirement for the succesful re-location of oxpeckers. An unsuccessful attempt to translocate oxpeckers is recorded by Davison (1963) while Grobler (1976) and Grobler (in press) record the successful re-introduction of yellow-billed oxpeckers in to the Rhodes Matopos National Park, Zimbabwe. This translocation was primarily to increase the distribution of the species, but also to provide a predator to feed on the ticks which were at a high density in the area. One of the main factors for the successful translocation was considered to be the presence of key hosts and an abundance of at least some major hosts. 
Another important factor to consider in translocating the birds is the presence of suitable nest sites. Although oxpeckers have been known to build their own nests in captivity (Kaiser-Benz 1975), they are generally tree hole nesters (Henderson 1958; Meinertzhagen 1959; Dowsett 1965; Mundy \& Cook 1974; Stutterheim 1976). Oxpeckers are basically fairly sedentary by habit (pers. obs.) and are reputed in some cases to return to the same host every day (Cave \& McDonald 1955), and may sometimes even remain on the hosts at night (Dowsett 1968). In contrast, Williams (1963) refers to the Red-billed Oxpecker as a partial migrant in east Africa, while Haldane (1951) records the numbers of yellow-billed oxpeckers varying considerably from year to year at Bufugi, Tanzania.

Where conditions are suitable in some of the smaller game refuges in South Africa, serious consideration should be given to the re-introduction of oxpeckers. Most of the smaller refuges have abnormally high tick densities and such an exercise would not only increase the distribution of the oxpecker, but also provide an effecient tick predator. Work carried out by Bezuidenhout of the Veterinary Research Institute at Onderstepoort (RSA) and Stutterheim of the Rand Afrikaanse University, has shown that a single bird can eat 6800 engorged bont-tick (Amblyomma spp.) larvae in 24 hours (see Nicholas \& Bird 1978). They also found 1666 ticks in the stomach of an oxpecker from the KNP, and found in controlled experiments involving cattle encaged with the birds, that the oxpeckers could control $98 \%$ adult blue ticks (Boophilus decoloratus), $60 \%$ of its nymphal stage and $40 \%$ of its larval stage. Although it is unlikely that oxpeckers could free a game refuge of ticks, or even effectively control the tick density, they would at least offer some form of control where none exists.

\section{Acknowledgements}

I would like to thank all those in the Department of Research and Information who assisted in various ways during the course of the study, in particular Mr P. Retief for advice and discussion on statistical analysis of the data.

\section{REFERENCES}

ATTWELL, R. I. G. 1966. Oxpeckers and their associations with mammals in Zambia. Puku 4: 17-48.

BENSON, S. W. and C. M. N. WHITE. 1957. Check list of the birds of Northern Rhodesia. Lusaka: Govt. Printer.

BROOKE, R. K. 1963. Birds around Salisbury, then and now. South African Avifauna Series of the Percy Fitzpatrick Institute of A frican Ormitho$\log y$ 9: 1-67. 
BUSKIRK, W. H. 1975. Substrate choices of oxpeckers. Auk 92(3): 604-606.

CAVE, F. O. and J. D. McDONALD. 1955. Birds of the Sudan. London: Oliver \& Boyd.

CLANCEY, P.A. 1964. The birds of Natal and Zululand. London: Oliver and Boyd.

DAVISON, E. 1963. Introduction of oxpeckers (Buphagus africanus and $B$. erythrorhynchus) into McIlwaine National Park. Ostrich 34: 172-173.

DOWSETT, R. J. 1965. On a nest of the Yellow-billed Oxpecker Buphagus africanus in Zambia. Bull. Br.Orn. Club 85: 133-135.

DOWSETT, R. J. 1968. Buphagus spp. on game animals at night. Bull. Br. Orn. Club 88: 130-132.

GOODWIN, D. 1963. Some behaviour of a captive Red-billed Oxpecker. Avicultural Magazine 69(3): 113-117.

GROBLER, J. H. 1976. The introduction of oxpeckers into the Rhodes Matopos National Park. Honeyguide 87: 23-25.

GROBLER, J. H. (in press). The re-introduction of oxpeckers (Buphagus africanus and B. erythrorhyncus) to the Rhodes Matopos National Park, Rhodesia. Biological Conservation.

GROBLER, J. H. and G. W. CHARSLEY. (in press). Host preference of the Yellow-billed Oxpecker Buphagus africanus in the Rhodes Matopos National Park, Rhodesia. S. Afr. J. Wildl. Res.

HALDANE, L.A. 1951. Birds of the Ngara district. Tanganyika Notes and Records 30: 39.

HENDERSON, R. 1958. The southern Red-billed Oxpecker. Ostrich 24: 132.

KAISER-BENZ, M. 1975. Breeding the Red-billed Oxpecker. Int. Zoo Yearbook 15: 120-123.

MEINERTZHAGEN, R. 1959. Pirates and predators. Edinburgh: Oliver \& Boyd.

MOREAU, R. F. 1933. The food of the Red-billed Oxpecker Buphagus erythrorhynchus (Stanley). Bull. ent. Res. 24: 325-335.

MUNDY, P. J. and A. W. COQK. 1974. Observations of the Yellowbilled Oxpecker Buphagus africanus in Northern Nigeria. Ibis 117: 504-506.

NICHOLAS, G. and M. BIRD. 1978. New ally for combating ticks. Farmers Weekly June 14: 10-11.

OLIVIER, R. C. D. and W. C. LAURIE. 1974. Birds associating with hippopotamusses. Auk 91(1): 169-170.

PITMAN, C. R. S. 1956. Oxpeckers. Zoo Life. Spring 21-25.

RICE, D. W. 1963. Birds associating with elephants and hippopotamusses. Auk 80(2): 196-197.

SMITHERS, R. H. N. 1964. A check list of the birds of the Bechuanaland Protectorate and the Caprivi Strip. Trustees of the National Museums of Southern Rhodesia.

STUTTERHEIM, C. J. 1976. The biology of the Red-billed Oxpecker, 
Buphagus erythrorhynchus (Stanley, 1814) in the Kruger National Park. MSc. Thesis, University of Pretoria.

STUTTERHEIM, C.J. 1977 a. Ectoparasites of the Red-billed Oxpecker in the Kruger National Park. S. Afr. J. Sci. 73: 281.

STUTTERHEIM, C. J. 1977b. Dimensions of the Red-billed Oxpecker in the Kruger National Park. Ostrich 48: 119-120.

STUTTERHEIM, C. J., P. J. MUNDY and A. W. COOK. 1976. Comparisons between the two species of oxpeckers. Bokmakierie 28(1): $12-14$.

VAN SOMEREN, V. D. 1951. The Red-billed Oxpecker and its relation to stock in Kenya. E. Afr. Agric. J. 17(1): 1-11.

WILLIAMS, J. G. 1963. A field guide to the birds of east and central Africa. London: Collins. 